\title{
Perforated duodenal diverticulum
} successfully treated with a combination of surgical drainage and endoscopic nasobiliary and nasopancreatic drainage: a case report

Ayako Shimada ${ }^{1,2^{*}}$, Koji Fujita', Minoru Kitago ${ }^{3}$, Shunsuke Ichisaka ${ }^{1}$, Keiichi Ishikawa', Hiroyuki Kikunaga', Koichiro Kumai ${ }^{1}$ and Hiroshi Miura ${ }^{4}$

\begin{abstract}
Background: Perforation of a duodenal diverticulum is a rare complication that may become fatal with a delay in appropriate treatment. However, the optimal treatment for perforated duodenal diverticulum remains controversial, ranging from conservative therapy to surgery including pancreatoduodenectomy.

Case presentation: The patient was a 60-year-old woman with no particular medical history who visited our hospital with chief complaints of continuous fever and right dorsal pain. Upon arrival, she had tenderness in the right upper quadrant of the abdomen. Laboratory data showed the elevation of inflammatory markers. Computed tomography revealed free air with abscess formation around the duodenum, which was diagnosed as duodenal perforation with abdominal abscess. We decided on emergent surgery, and we identified the perforation site on the dorsal side of the second portion of the duodenum intraoperatively. However, the inflammation around the perforation site was severe, and it was difficult to perform primary closure or dissection of the perforated diverticulum. Therefore, we finished surgery by placing four indwelling intra-abdominal tubes. Since postoperative day (POD) 1, the elevation of inflammation markers appeared to be uncontrollable, owing to the leakage of bile and pancreatic juice. We decided to perform endoscopic retrograde cholangiopancreatography on POD 2, and inserted endoscopic nasobiliary drainage and nasopancreatic drainage tubes. The patient showed a good postoperative course and was discharged on POD 57.
\end{abstract}

Conclusions: Endoscopic nasobiliary and nasopancreatic drainage in combination with surgical drainage may be an effective treatment for perforated duodenal diverticulum.

Keywords: Perforation, Duodenal diverticulum, Endoscopic treatment

\footnotetext{
*Correspondence: supershimada@yahoo.co.jp

'Department of Surgery, Hino Municipal Hospital, 4-3-1 Tamadaira, Hino,

Tokyo 191-0062, Japan

2Department of Hepato-Biliary-Pancreatic and Gastrointestinal Surgery,

International University of Health and Welfare Narita Hospital, Narita, Japan

Full list of author information is available at the end of the article
}

\section{Springer Open}

(c) The Author(s). 2020 Open Access This article is licensed under a Creative Commons Attribution 4.0 International License, which permits use, sharing, adaptation, distribution and reproduction in any medium or format, as long as you give appropriate credit to the original author(s) and the source, provide a link to the Creative Commons licence, and indicate if changes were made. The images or other third party material in this article are included in the article's Creative Commons licence, unless indicated otherwise in a credit line to the material. If material is not included in the article's Creative Commons licence and your intended use is not permitted by statutory regulation or exceeds the permitted use, you will need to obtain permission directly from the copyright holder. To view a copy of this licence, visit http://creativecommons.org/licenses/by/4.0/. 


\section{Background}

Duodenal diverticulum is a relatively common disease and usually asymptomatic unless complications occur [1]. Perforation of a duodenal diverticulum is a rare complication that may become fatal with a delay in diagnosis owing to bile and pancreatic juice leakage [2-7]. However, the most appropriate treatment for perforated duodenal diverticulum remains disputable, which ranges from conservative therapy to surgery, including pancreatoduodenectomy. In addition to these treatments, we consider that endoscopic treatment may play a large role to control the leakage of bile and pancreatic juice $[8,9]$. Here, we experienced a case with a perforated duodenal diverticulum, which we successfully treated by surgery followed by endoscopic drainage of the bile and pancreatic ducts.

\section{Case presentation}

The patient was a 60-year-old female who came to the hospital with chief complaints of fever and right dorsal pain. She had no particular past medical history. She had continuous fever lasting for 1 week and had visited a nearby clinic. Because the laboratory findings revealed the elevation of inflammation markers, she was referred to our hospital for further examination and treatment. Her vital signs showed a body temperature of $37.2^{\circ} \mathrm{C}$ and heart rate of 119 beats/min. On physical examination, she complained of abdominal pain in the right upper quadrant of the abdomen with no signs of peritoneal irritation, and right costovertebral angle tenderness was also detected. Laboratory data were remarkable with elevation of inflammatory markers (white blood cell count, $12,900 / \mathrm{mm}^{3}$; C-reactive protein, 23.3 $\mathrm{mg} / \mathrm{ml}$ ) and elevation of hepatic bile duct enzymes. Computed tomography (CT) revealed free air with abscess formation surrounding the second portion of the duodenum (Fig. 1). We diagnosed as duodenal perforation with abdominal abscess and decided to perform immediate exploratory laparotomy. During surgery, the perforation site was found to be at the dorsal side of the descending limb of the duodenum. The abscess was formed due to the perforation of a duodenal diverticulum into the retroperitoneum. However, the inflammation surrounding the perforation was too severe, and it was difficult to perform primary closure or dissection of the diverticulum (Fig. 1); therefore, we finished the surgery by placing four intraperitoneal tubes as shown in Fig. 2. The total operation time was $105 \mathrm{~min}$, and the blood loss was $136 \mathrm{ml}$. Since postoperative day (POD) 1, the leakage of pancreatic juice and bile was continuing (amylase and total bilirubin in the drainage fluid, 105, $410 \mathrm{IU} / \mathrm{l}$ and $27.4 \mathrm{mg} / \mathrm{dl}$, respectively), and the elevation of inflammation markers appeared to be uncontrollable. In order to manage the leakage of pancreatic juice and
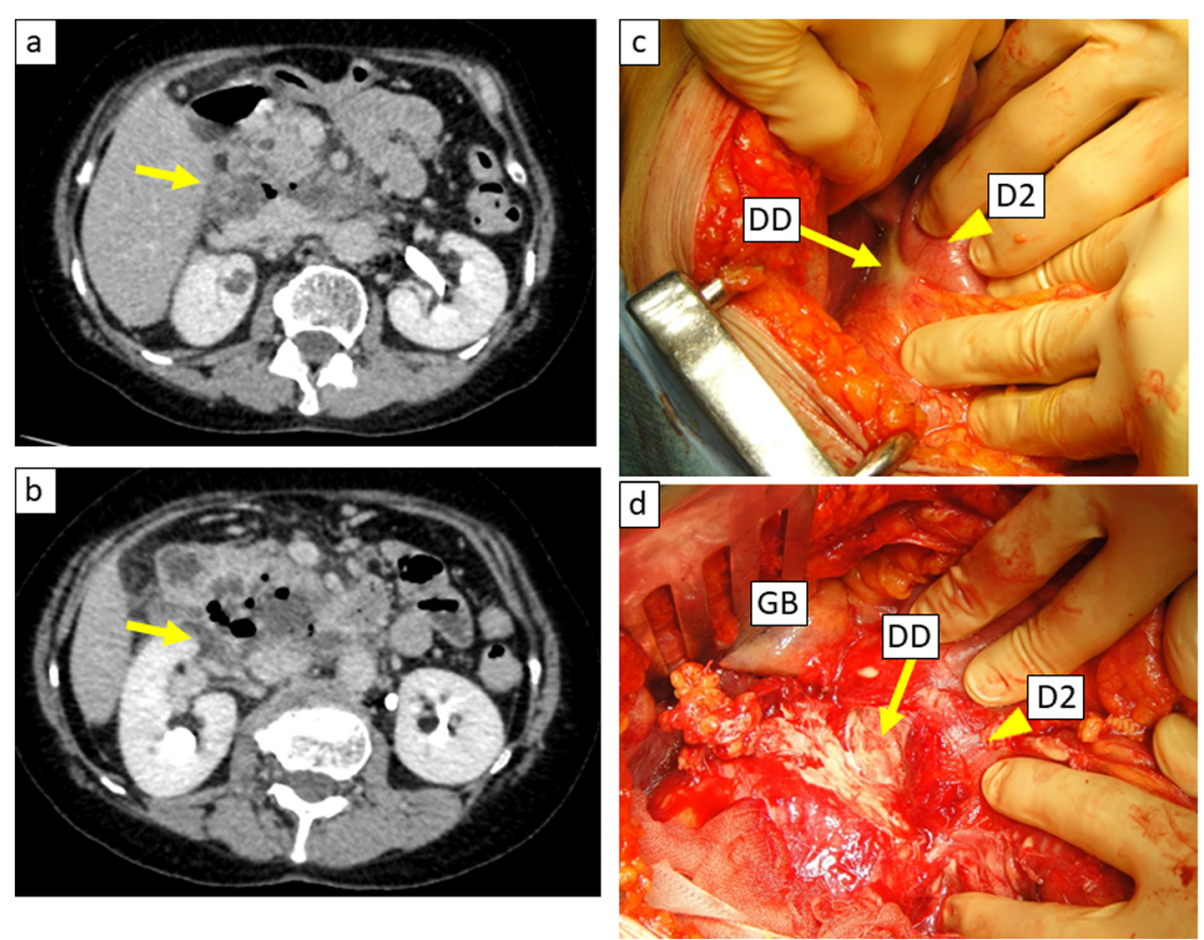

Fig. $1 \mathbf{a}$, b Computed tomography images showing abscess with free air surrounding the second portion of the duodenum (yellow arrow). $\mathbf{c}$, $\mathbf{d}$ Surgical findings of the perforation site. The perforated duodenal diverticulum (DD, yellow arrow) was identified on the dorsal side of the second portion of the duodenum (D2, yellow arrowhead; GB, gallbladder) 

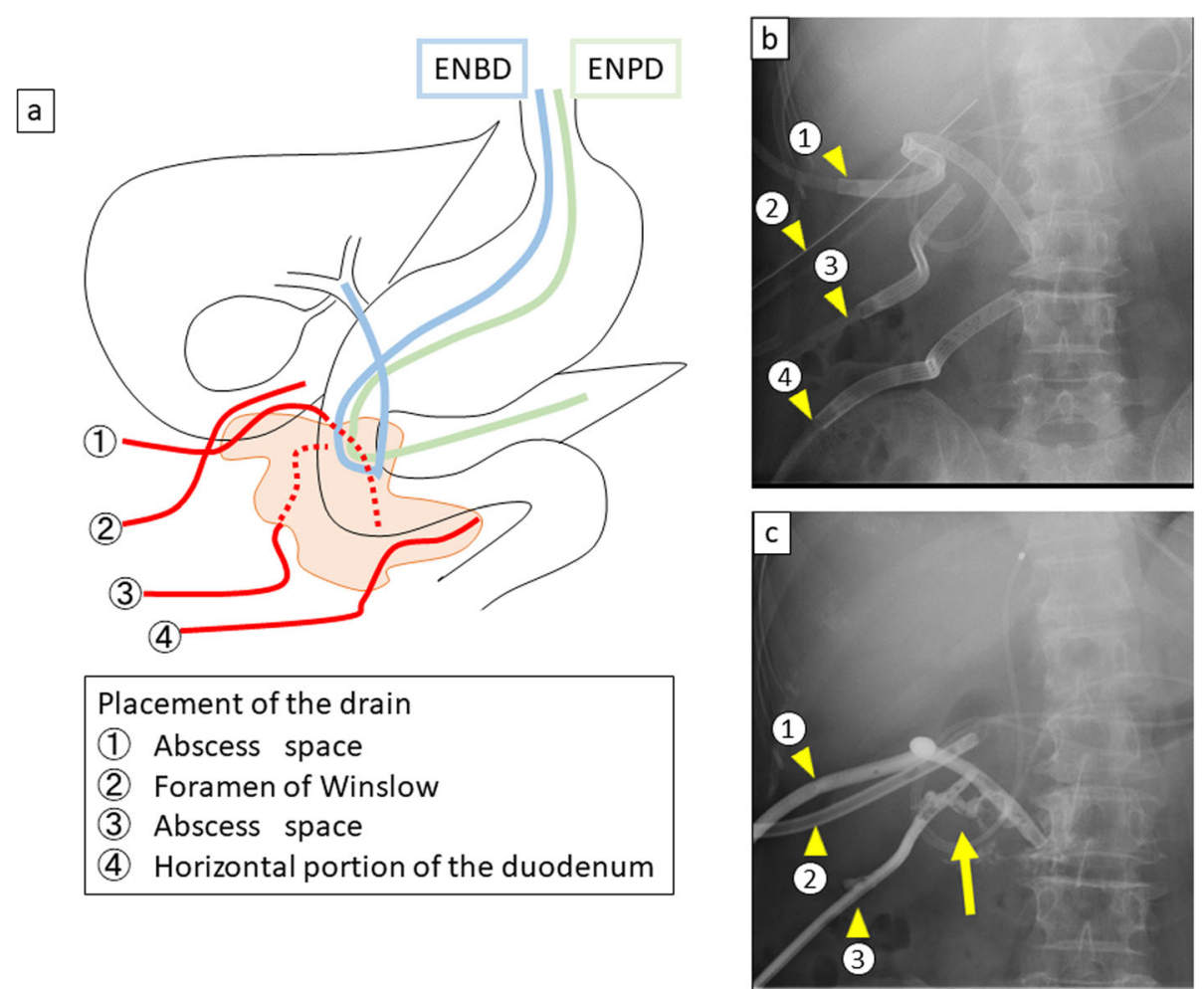

Fig. 2 a The scheme of the treatment strategy. Four indwelling tubes (1) abscess space, (2) foramen of Winslow, (3) abscess space, and (4) horizontal part of the duodenum) were placed intraoperatively. Furthermore, endoscopic nasobiliary drainage (ENBD) and nasopancreatic drainage (ENPD) tubes were placed on postoperative day (POD) 2. b The picture after endoscopic retrograde cholangiopancreatography (ERCP) on POD 2. Yellow arrowheads show the placement of four indwelling tubes. $\mathbf{c}$ The picture of contrast radiography on POD 20, which revealed a fistula between the abscess space and the duodenal diverticulum (yellow arrow). The drain placed on the horizontal part of the duodenum was already removed, and yellow arrowheads show that the three indwelling drains remained

bile, we decided to perform endoscopic retrograde cholangiopancreatography on POD 2, and we inserted endoscopic nasobiliary drainage (ENBD) and nasopancreatic drainage (ENPD) tubes. After endoscopic drainage, the amount of drainage decreased, and the drainage fluid became more serous. On POD 6, we began irrigation through the drainage tube in order to continuously wash out the abscess. The contrast radiography on POD 20 revealed a fistula between the abscess and the duodenal diverticulum which gradually decreased in size (Fig. 2). We removed the ENPD tube on POD 34 and the ENBD tube on POD 41. We started oral ingestion on POD 42, and the patient was discharged on POD 57. Upper gastrointestinal endoscopy performed 2 months postoperatively revealed the duodenal diverticulum containing food debris (Fig. 3).

\section{Discussion}

The incidence of duodenal diverticula detected at autopsy is reported to be as high as $22 \%$ [10]. Duodenal diverticula are commonly found in the parapapillary of Vater and the horizontal portion and ascending portion of the duodenum. Most diverticula are asymptomatic, and only $5 \%$ of patients experience complications such as acute diverticulitis, hemorrhage, perforation, biliary obstruction, and pancreatitis $[2,11]$. The causes of perforated duodenal diverticulum can be diverticulitis, ulceration, enterolithiasis, foreign bodies, and blunt abdominal trauma, and diverticulitis is reported to be the most common cause among all [7, 12]. Perforated duodenal diverticulum is a rare but serious complication associated with a significant mortality rate of up to $30 \%$ [13]. Yeh reviewed 186 cases of perforated duodenal diverticulum reported in the literature from 1907 to 2016, and the overall mortality was found to be $16 \%$ [14].

A clinical presentation of a perforated duodenal diverticulum is highly valuable, but it is difficult to diagnose at first sight. Some patients may complain of back pain, especially if the perforation is retroperitoneal. Other symptoms will be fever, nausea, and vomiting [15]. CT is effective for the diagnosis showing extraluminal gas and extraluminal fluid, and it is the most useful modality in the diagnosis of a perforated duodenal diverticulum [15].

A total of 201 cases of perforated duodenal diverticulum have been reported worldwide since 1907 up 

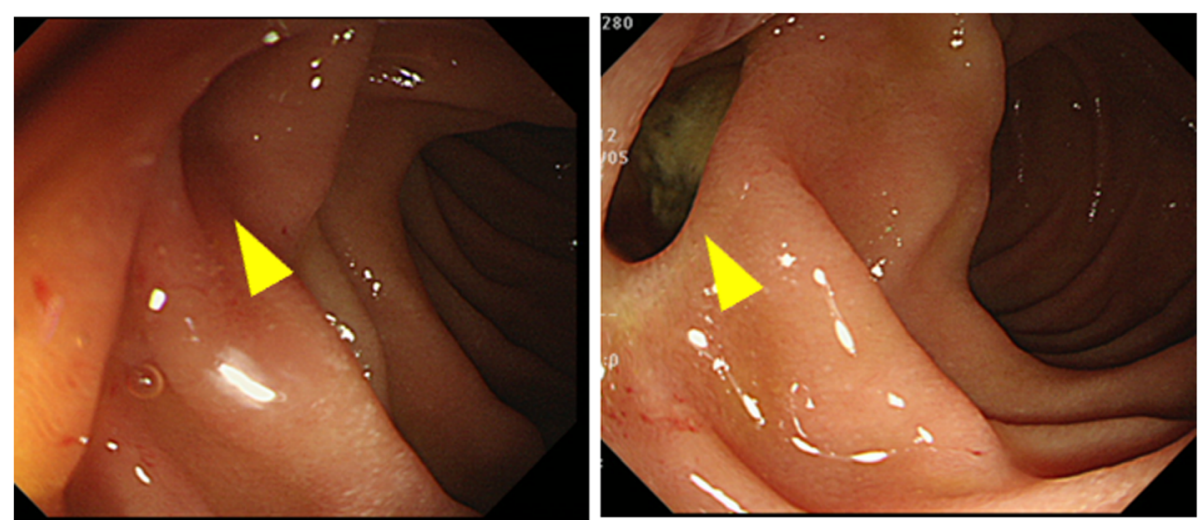

Fig. 3 Upper gastrointestinal endoscopy performed 2 months after surgery revealed the presence of food debris in the duodenal diverticulum (yellow arrowhead)

to now $[3-5,7,13-24]$. Including our single case, a summary of all 202 cases is provided in Table 1. The most frequently performed treatment for perforated duodenal diverticulum has been diverticulectomy. A total of $17 \%$ of all reported cases were treated by conservative therapy. Applicable surgical procedures should be determined based on the severity of inflammation surrounding the perforation site. If the inflammation is too severe and the risk of anastomosis leakage may be unavoidable, we may be forced to

Table 1 Reported cases of perforated duodenal diverticulum

\begin{tabular}{|c|c|c|c|}
\hline \multirow[b]{2}{*}{ Age } & & \multicolumn{2}{|l|}{$n=202$} \\
\hline & & Mean 64 & $(5-94)$ \\
\hline \multirow[t]{3}{*}{ Gender } & Male & 69 & $(34.2 \%)$ \\
\hline & Female & 128 & $(63.3 \%)$ \\
\hline & Not specified & 5 & $(2.5 \%)$ \\
\hline \multirow[t]{5}{*}{ Location } & Second portion & 159 & $(78.7 \%)$ \\
\hline & Third portion & 26 & $(12.8 \%)$ \\
\hline & Fourth portion & 5 & $(2.5 \%)$ \\
\hline & Second and third portions & 4 & $(2.0 \%)$ \\
\hline & Not specified & 8 & $(4.0 \%)$ \\
\hline \multirow[t]{16}{*}{ Treatment } & Surgical treatment & 168 & $(83.0 \%)$ \\
\hline & Diverticulectomy & 67 & $(33.2 \%)$ \\
\hline & Diverticulectomy + other surgical procedures & 45 & $(22.3 \%)$ \\
\hline & Primary closure & 5 & $(2.5 \%)$ \\
\hline & Duodenojejunostomy/gastrojejunostomy & 5 & $(2.5 \%)$ \\
\hline & Duodenectomy & 3 & $(1.5 \%)$ \\
\hline & Gastrectomy & 1 & $(0.5 \%)$ \\
\hline & Pancreatoduodenectomy & 3 & $(1.5 \%)$ \\
\hline & Drainage/laparotomy & 25 & $(12.5 \%)$ \\
\hline & ENBD/ENPD with surgical drainage & 1 & $(0.5 \%)$ \\
\hline & Not specified & 10 & $(5.0 \%)$ \\
\hline & Conservative treatment & 34 & $(17.0 \%)$ \\
\hline & Bowel rest/antibiotics & 17 & $(8.5 \%)$ \\
\hline & Percutaneous drainage & 2 & $(1.0 \%)$ \\
\hline & Endoscopic abscess drainage & 3 & $(1.5 \%)$ \\
\hline & No surgery/autopsy only & 12 & $(6.0 \%)$ \\
\hline
\end{tabular}


dissect the intestine, leading to pancreatoduodenectomy [3-6]. However, the surgical procedure may be highly invasive for the patients. Instead of these invasive treatments, more conservative treatment is drawing our attention. Eeckhout et al. reported the endoscopic approach to the abdominal abscess due to a perforated duodenal diverticulum [8]. To date, there are only few reports of endoscopic treatment selected for perforated duodenal diverticula [15].

In the present case, surgical drainage for abdominal abscess was initially performed; however, the inflammation was too severe to safely perform any surgical procedure in addition to the drainage. In order to irrigate the abscess cavity postoperatively, we placed two drainage tubes into the abscess space and finished without performing omentum patch. CT-assisted percutaneous drainage may be the choice which can be the alternative to the surgery; however, the abscess which was formed gradually in 1 week was very large, and we considered that percutaneous drainage alone might be insufficient to manage the abscess. Instead, we decided to perform laparotomy with sufficient drainage and planned for postoperative irrigation to continuously wash out the abscess. We then performed ENBD and ENPD to control the leakage of bile and pancreatic juice. Endoscopic treatment can be selected not only for direct abscess drainage, but also for bile duct and pancreatic duct drainage. We believe that endoscopic treatment may help these patients from the worst situation by controlling the leakage of bile and pancreatic juice. With regard to our case, if we could not successfully perform endoscopic treatment, we were thinking of performing pancreatoduodenectomy. Fortunately, the endoscopic challenge was effective in our case. Consequently, we could avoid performing any further invasive surgery for these patients in addition to the drainage. To the best of our knowledge, our case is the first to show the effectiveness of ENBD and ENPD in combination with surgical drainage for perforated duodenal diverticulum.

When we encounter a perforated duodenal diverticulum, any possible leakage of bile and pancreatic juice that may be difficult to control only by conservative therapy should be carefully assessed. Although we think that ENBD and ENPD may be effective for the treatment of perforated duodenum diverticulum, surgery should be considered at any time if the situation gets worse.

\section{Conclusions}

ENBD and ENPD can be an effective treatment for perforated duodenal diverticulum. However, if we choose conservative treatment for patients with perforated duodenal diverticulum, we should not hesitate to proceed to surgical intervention at any time the situation gets worse.

\section{Abbreviations}

POD: Postoperative day; CT: Computed tomography; ENBD: Endoscopic nasobiliary drainage; ENPD: Endoscopic nasopancreatic drainage

\section{Acknowledgements}

None

\section{Authors' contributions}

AS reported the case and drafted the manuscript. AS, KF, and SI performed the surgery, and KF and SI helped draft the manuscript. MK performed the endoscopic treatment for the patient and helped draft the manuscript. Kl, $\mathrm{HK}, \mathrm{KK}, \mathrm{TY}$, and HM participated in revising the manuscript critically. All authors declare that they contributed to this article and that they read and approved the final manuscript.

\section{Funding}

The authors declare that they have no financial support in association with this case report

\section{Availability of data and materials}

All data generated or analyzed during this study are included in this published article.

Ethics approval and consent to participate

None

Consent for publication

Consent to publish was obtained from the patient.

\section{Competing interests}

All authors declare that they have no conflict of interest.

\section{Author details}

${ }^{1}$ Department of Surgery, Hino Municipal Hospital, 4-3-1 Tamadaira, Hino, Tokyo 191-0062, Japan. ²Department of Hepato-Biliary-Pancreatic and Gastrointestinal Surgery, International University of Health and Welfare Narita Hospital, Narita, Japan. ${ }^{3}$ Department of Surgery, Keio University School of Medicine, Shinjuku, Japan. ${ }^{4}$ Department of Radiology, Hino Municipal Hospital, Hino, Japan.

Received: 27 March 2020 Accepted: 29 May 2020

Published online: 08 June 2020

\section{References}

1. Oddo F, Chevallier P, Souci J, Baque J, Buckley MJ, Fabiani P, et al. Radiologic aspects of the complications of duodenal diverticula. J Radiol. 1999:80(2):134-40.

2. Bittle MM, Gunn ML, Gross JA, Rohrmann CA. Imaging of duodenal diverticula and their complications. Curr Probl Diagn Radiol. 2012;41(1):20-9.

3. Philip J, Cocieru A. Pancreatoduodenectomy in patient with perforated duodenal diverticulum and peritonitis: case report. Int J Surg Case Rep. 2019;58:48-9.

4. Branco C, Teresa C, Dina L, Antonio G. Perforated duodenal diverticulum: a rare complication in a common condition. BMJ Case Rep. 2017. https://doi. org/10.1136/bcr-2017-219881.

5. Sahned J, Hung Fung S, Mohammed Saeed D, Misra S, Park IS. Duodenal diverticulitis: to operate or not to operate? Cureus. 2019. https://doi.org/10. 7759/cureus.6236.

6. Schinueriger B, Vorburger SA, Banz VM, Schoepfer AM, Candinas D. Diagnosis and management of the symptomatic duodenal diverticulum: a case series and a short review of the literature. J Gastrointest Surg. 2008; 12(9):1571-6.

7. Kim KH, Park SH. Conservative treatment of duodenal diverticulitis perforation: a case report and literature review. Open Access Emerg Med. 2018;10:101-4.

8. Eeckhout G, Vanstiphous J, Van Pottelbergh I, Leyman P, Vandervoort J, De Man M, et al. Endoscopic treatment of a perforated duodenal diverticulum. Endoscopy. 2000;32(12):991-3.

9. Tamura $Y$, Hayakawa M, Isogawa M, Togashi $T$, Igarashi M, Takahashi $S$, et al. Duodenal diverticulitis accompanied by abscess formation treated 
successfully using an endoscopic nasobiliary catheter: a case report. Clin J Gastroenterol. 2017;10(3):240-3.

10. Ackermann W. Diverticula and variations of the duodenum. Ann Surg. 1943; 117(3):403-13

11. Okabuchi N, Brouzes S. Management of complicated duodenal diverticula. J Visc Surg. 2013;150(3):173-9.

12. Thorson CM, Ruiz PS, Roeder RA, Sleeman D, Casillas VJ. The perforated duodenal diverticulum. Arch Surg. 2012;147(1):81-8.

13. Juler GL, List JW, Stemmer EA, Connolly JE. Perforating duodenal diverticulitis. Arch Surg. 1969;99(5):572-8.

14. Yeh TC. Laparoscopic resection of perforated duodenal diverticulum - a case report and literature review. Int J Surg Case Rep. 2016;28:204-10.

15. Moysidis M, Paramythiotis D, Karakatsanis A, Amanatidou E, Psoma E, Mavropoulou $X$, et al. The challenging diagnosis and treatment of duodenal diverticulum perforation: a report of two cases. BMC Gastroenterol. 2020. https://doi.org/10.1186/s12876-019-1154-2.

16. Duarte B, Nagy KK, Cintron J. Perforated duodenal diverticulum. Br J Surg. 1992;79(9):877-81.

17. Glener J, Poris S, Foles B, Harmon R. Perforated duodenal diverticulum case report. Int J Surg Case Rep. 2016;29:100-2.

18. Nepal P, Maemura K, Mataki Y, et al. Management of horizontal duodenal perforation: a report of three cases and review of literature. Surg Case Rep. 2017;3(1):119.

19. Shirobe T, Kawakami H, Abe S, Yokochi T. Retroperitoneal perforation arising from duodenal diverticulum treated by endoscopic drainage: a case report. Clin Case Rep. 2017:5(5):654-7.

20. Degheili JA, Abdallah MH, Haydar AA, Moukalled A, Hallal AH. Perforated duodenal diverticulum treated conservatively: another two successful cases. Case Rep Surg. 2017;2017:4045970. https://doi.org/10.1155/2017/4045970.

21. Fan HS, Talbot ML. Successful management of perforated duodenal diverticulum by use of endoscopic drainage. VideoGIE. 2016;2(2):29-31.

22. Shen $Y$, Leong MKF. Perforated duodenal diverticulum with subtle pneumoretroperitoneum on abdominal X-ray. Case Rep Emerg Med. 2017; 2017:7089573. https://doi.org/10.1155/2017/7089573.

23. Khan K, Saeed S, Maria H, et al. Duodenal diverticular perforation after small bowel obstruction: A Case Report. Case Rep Surg. 2018;2018:6197828. https://doi.org/10.1155/2018/6197828.

24. Kabelitz N, Brinken B, Bumm R. Retroperitoneal perforation of a duodenal diverticulum containing a large enterolith after RouX-en-Y bypass and cholecystectomy. J Surg Case Rep. 2020;2020(2):rjz383. Published 2020 Feb 10. doi: https://doi.org/10.1093/jscr/rjz383.

\section{Publisher's Note}

Springer Nature remains neutral with regard to jurisdictional claims in published maps and institutional affiliations.

\section{Submit your manuscript to a SpringerOpen ${ }^{\circ}$ journal and benefit from:}

- Convenient online submission

- Rigorous peer review

- Open access: articles freely available online

- High visibility within the field

- Retaining the copyright to your article

Submit your next manuscript at $\boldsymbol{\nabla}$ springeropen.com 